\title{
Addressing Female Iron-Deficiency Anaemia in India: Is Vegetarianism the Major Obstacle?
}

\author{
Anu Rammohan, ${ }^{1}$ Niyi Awofeso, ${ }^{2,3}$ and Marie-Claire Robitaille ${ }^{1}$ \\ ${ }^{1}$ Discipline of Economics, School of Business, University of Western Australia, 35 Stirling Highway, Perth, WA 6009, Australia \\ ${ }^{2}$ School of Population Health (M431), University of Western Australia, 35 Stirling Highway, Perth, WA 6009, Australia \\ ${ }^{3}$ School of Public Health, University of New South Wales, Sydney, NSW 2052, Australia
}

Correspondence should be addressed to Niyi Awofeso, niyiawofeso@hotmail.com

Received 9 September 2011; Accepted 29 September 2011

Academic Editors: E. Alderete and C. Siffel

Copyright ( $) 2012$ Anu Rammohan et al. This is an open access article distributed under the Creative Commons Attribution License, which permits unrestricted use, distribution, and reproduction in any medium, provided the original work is properly cited.

\begin{abstract}
Objectives. We examined the influence of vegetarian diet on the risk of developing anaemia among Indian women and suggest initiatives for addressing diet-related iron-deficiency anaemia. Methods. We analysed data on diet, social class, and haemoglobin levels from the nationally representative Indian National Family and Health Survey 2005/06 for a sample of 81,301 women aged 1549 years using logistic regression models. Results. After controlling for individual-level factors and household level socioeconomic characteristics, daily consumption of meat, fish, and eggs was associated with lower odds of being moderately or severely anaemic. Our analysis also revealed that economic characteristics such as being from higher wealth quintiles, being in paid employment, and rural residence reduced the odds of having iron-deficiency anaemia among Indian women. Discussion. As a large proportion of Indians subsist on iron-poor vegetarian diets for religious, economic, and cultural reasons, large-scale iron supplementation and fortification of commonly consumed vegetarian foodstuffs constitute a feasible, culturally appropriate, and cost-effective strategy for addressing this major public health problem. Consumption of cheap iron-rich foodstuffs should be promoted. Effective poverty alleviation and hookworm prevention programs are also important. Large-scale cohort and intervention studies are urgently required to further define the influence of vegetarianism on iron deficiency anaemia in India.
\end{abstract}

\section{Introduction}

Anaemia affects over 800 million women worldwide. In India, it is classified as a major public health problem as it is estimated that $52 \%$ of nonpregnant women of reproductive age are anaemic [1]. Although the primary cause of anaemia is iron-deficiency, it is seldom present in isolation. More frequently it coexists with a number of other causes, such as malaria, parasitic infection, nutritional deficiencies, and haemoglobinopathies. The importance of iron-deficiency as cause of anaemia varies by region. While as low as 50\% of anaemia in sub-Saharan Africa may be attributable to iron-deficiency (due to high prevalence of HIV, hookworm, malaria, and other infectious diseases) the proportion of anaemia caused by iron-deficiency increases to over $70 \%$ among premenopausal women in India [2,3].

According to the World Health Organization's 2009 Global health risks' report [4], iron-deficiency anaemia accounted for 400,000 deaths and 1.5\% of the global Disability Adjusted Life Years in 2004. This cost is disproportional borne by developing nations as $60 \%$ of the morbidity and $95 \%$ of the mortality related to iron-deficiency are derived from the poorest nations of the world. South Asia and sub-Saharan Africa bear about $70 \%$ of the global mortality burden attributable to iron-deficiency anaemia.

Iron-deficiency also has important consequences for the future generations, as iron-deficiency anaemia increases the risk for preterm labour, low birth weight, infant mortality and predicts iron-deficiency in infants after 4 months of age $[5,6]$. Anaemia, of which iron-deficiency is the major contributor, accounts for $3.7 \%$ and $12.8 \%$ of maternal deaths during pregnancy and childbirth in Africa and Asia, respectively [7]. It also leads to cognitive deficits and reduced intellectual performance among school children [8]. In communities where iron-deficiency is highly prevalent, successful iron supplementation results in the disappearance of 
anaemia as a public health problem except where malaria and HIV or hookworm infection rates are high [9].

The World Health Organization defines iron-deficiency anaemia as a condition whereby either individual haemoglobin levels are two standard deviations below the distribution mean, or more than $5 \%$ of a given population has haemoglobin levels that are two standard deviations below the distribution mean, in an otherwise normal population of individuals from the same gender and age, living at the same altitude [10]. Significant public health implications are more commonly associated with moderate to severe anaemia, defined as haemoglobin level below $10 \mathrm{~g} / \mathrm{dL}$. A focus on subpopulations experiencing moderate to severe anaemia helps to better define the problem of iron-deficiency anaemia in terms of functional consequences rather than normative indicator distributions, thus potentially improving the impact of advocacy efforts and reducing the tendency towards false positive epidemics of anaemia. In India, a focus on moderate to severe forms of anaemia is particularly appropriate given the high prevalence of anaemia and the public health significance of moderate and severe anaemia [3].

Despite increased national and international awareness and recent governmental intervention programs, the prevalence of anaemia among Indian women has remained higher than $45 \%$ since 1990 , and anaemia trends remain strongly correlated with iron-deficiency [11-14]. A 2007 Indian government " 12 by 12 initiative", aimed at ensuring that all Indian adolescents have $12 \mathrm{~g} / \mathrm{dL}$ haemoglobin by 2012, listed the main causes of anaemia in India as low dietary intake, poor availability of iron, chronic blood loss due to hookworm infestation, and malaria [15].

Vegetarianism, defined as the exclusive consumption of plant-based diets, is a common dietary pattern in India, dating back to at least 2500 years. In the United States, where about $7 \%$ of the population is estimated to be vegetarian, holding less traditional values and more altruistic values are associated with a high likelihood of vegetarianism [16]. In India, vegetarianism is influenced in part by adherence to the ethical teachings of ahimsa or "nonviolence" inherent in Hinduism, Buddhism, and Jainism. Vegetarian-style diets constitute a common dietary pattern in India, dating back to at least 2500 years, with Indians constituting about $70 \%$ of the world's population who adhere to vegetarian-style diets. About $75 \%$ of Indian vegetarians are lactovegetarians (i.e., do not consume meat or eggs, with no prohibition for milk or other dairy products), with up to $25 \%$ being lactovovegetarians (who do not eat meat, with no prohibition on eggs and dairy products). Less than $1 \%$ of Indians are vegans, who do not eat any animal products at all [17]. Vegetarianism has important implications for maternal iron-deficiency in India, in terms of the availability and chemical form of iron in plant-based foods. Although a vegetarian diet is likely to contain iron in amounts equivalent to that in omnivorous diets, animal-based haemoglobin iron is better absorbed (15-40\% absorption) compared with plant-based nonhaemoglobin iron (1-15\% absorption), despite variations in body iron stores [18]. Nutritionists recommend that vegetarians need to increase dietary iron by $80 \%$ to compensate for a lower iron availability of $10 \%$ from a vegetarian diet compared with $18 \%$ from an omnivorous diet [19]. This recommendation constitutes a major challenge in India where the majority of vegetarians subsist on inadequate quantities of iron-poor staples such as lentils, wheat bread, green peppers, and rice.

A modified food guide pyramid for vegetarians entails obtaining 32-36 mg of iron daily in a 2000 calorie diet containing 8 servings of grains, 3 of vegetables, 2.5 of green leafy vegetables, 1.5 of fruit, 2.5 of beans and protein foods, 3 of dairy or nonfortified dairy, 1.5 of nuts and seed, and 2.5 of oils [20]. The authors' lived experience in India indicates that the vast majority of Indian vegetarians are unable to afford to eat such varied vegetarian meals in the quantities suggested. In addition, affordable foodstuffs such as wheat bread contain high levels of phytates, while tea, a popular beverage in India, is high in tannic acid content. Phytates and tannins inhibit iron absorption $[21,22]$.

Most popular Indian vegetarian recipes fall short of the daily requirements when calculated for iron intake, even when it is assumed that such vegetarian diets are consumed in large quantities (http://www.nestle.com.au/NutritionAndHealth/Calculators/pages/IronCalculator.aspx). In industrialized nations, affordable and accessible fortified vegetarian foods, such as breakfast cereals, reduce the risk of iron-deficiency. Furthermore, supplemental iron is affordable in Western nations, and its targeted use for groups at high risk for iron-deficiency anaemia, such as pregnant women, is better coordinated than in India $[23,24]$. In contrast, most Indian staple foods are produced or grown locally, and most commonly consumed foods are not fortified with iron. For instance, in 2007, only 91 millers in 4 Indian states were fortifying their wheat flour with support from the Micronutrient Initiative, reaching an estimated 8.56 million people in a country of 1.15 billion people [25]. A popular food item in India is beans. Beans have relatively high iron content, but only $2 \%$ is absorbed from the most commonly consumed variety of beans in India, Phaseolus vulgaris. Other varieties of beans, such as soybean, are more easily absorbed-iron absorption from soybeans is about 30\% in iron deficient women, which is similar to that from meat or iron sulphate tablets, because $90 \%$ of the iron in soybeans is in the form of ferritin-soybean is not a popular food item in India $[26,27]$.

This study examines the influence of vegetarian diets on the prevalence of maternal anaemia in India. Using data from the 2005-06 Indian National Family and Health Survey (NFHS-3), the authors demonstrate the strong links between dietary patterns, particularly vegetarianism, and anaemia. Diet-related recommendations for addressing this major public health problem are proposed.

\section{Methods}

India's three National Family Health Surveys (NFHS) are widely regarded as reliable storehouses of demographic and health data [28]. The data for this study were derived from the latest survey, NFHS-3, conducted in 2005-06, with a sample size of 81,301 women aged between 15-49 years. 
The NFHS-3 is the third in a series of nationwide cross-sectional surveys where interviews were conducted with 124,385 women aged 15-49 years from all the 29 Indian states. The urban and rural samples within each state were drawn separately, and the sample within each state was allocated proportionally to the size of the state's urban and rural populations. The analysis in this paper is based on questions from the women's questionnaire, where information was collected on haemoglobin levels, household-level socioeconomic characteristics, demographic and labour market conditions, and the dietary habits of female respondents. The determination of the overall sample size for NFHS-3 was governed by the magnitude of the key indicators, the subgroups for which the indicators are required (e.g., HIV prevalence in six states), the desired level of precision of the estimates (e.g., haemoglobin test only for anaemia), the availability of resources, and logistical considerations. An initial target sample size of 1,500 completed interviews with ever-married women in states with a 2001 Census population less than 5 million, 3,000 completed interviews with ever married women in states with a 2001 Census population between 5 and 30 million, and 4000 completed interviews with evermarried women in states with a population of more than 30 million. The initial target sample size in Uttar Pradesh, the largest Indian state with about $16 \%$ of the country's population, was fixed at 10,000 ever-married women. The target sample size for the eight cities with separate slum and nonslum estimates was fixed at a minimum of 2,000 interviews with ever-married women (equally distributed between slum and nonslum areas of each city).

Haemoglobin concentration is a widely used measure of anaemia. A drop of blood was collected in a microcuvette for anaemia testing, making adjustments for altitude. Although haemoglobin measurements are considered less valid than serum ferritin as a measure of iron-deficiency and irondeficiency anaemia, a strong correlation exists between haemoglobin concentration and serum ferritin levels [29, 30]; haemoglobin concentration monitoring is more useful in monitoring the effectiveness of interventions to remedy iron-deficiency, and haemoglobin levels are easier to measure under field conditions [10]. Three levels of severity of anae mia are distinguished: mild anaemia $(10.0-10.9 \mathrm{~g} / \mathrm{dL}$ for pregnant women, $10.0-11.9 \mathrm{~g} / \mathrm{dL}$ for nonpregnant women), moderate anaemia (7.0-9.9 g/dL), and severe anaemia (less than $7.0 \mathrm{~g} / \mathrm{dL}$ ). Our focus in this paper is on moderate and severe anaemia, based on the established functional consequences of this level of anaemia, such as up to $30 \%$ decline in work capacity and performance as well as suboptimal birth outcomes among women in the reproductive and economically productive age group of 15-49 years. Moderate to severe iron-deficiency anaemia is more closely correlated with haemoglobin concentration-the only estimate used in the NFHS-3 - than mild iron-deficiency anaemia [10, 29]. Table 1 indicates that the prevalence of severe and moderate anaemia in the NFHS-3 cohort of women aged 15-49 years was $16 \%$. Based on estimates indicating that iron-deficiency anaemia accounts for 70-90\% of moderate to severe anaemia among women in the 15-49 years age group [30-32], it may be surmised that the prevalence of iron-deficiency anaemia

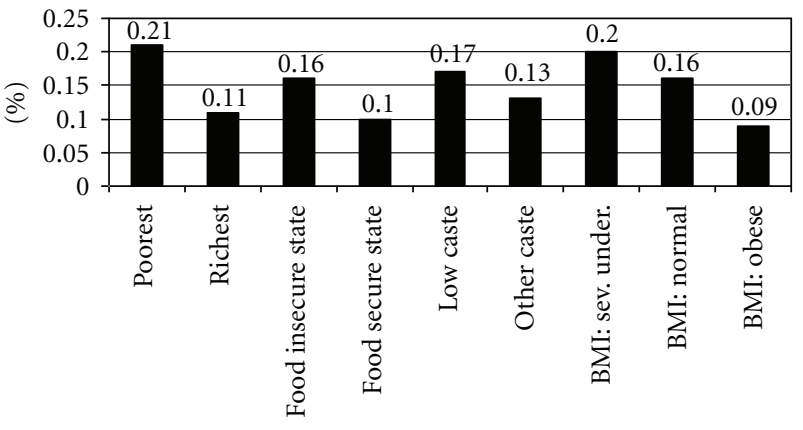

Characteristics

FIgURE 1: Percentage of the population that is anaemic by selected characteristics. Source: authors' calculation based on NFHS-3.

among women with moderate to severe anaemia in the NFHS-3 dataset was at least $11 \%$.

Respondents were asked how often they consume various types of food (daily, weekly, occasionally, or never). These types of food consumed were categorised into four groups (i) meat, fish, and eggs; (ii) milk and dairy products; (iii) fruits; (iv) pulses and green vegetables.

Basic demographic data were pregnancy status, number of children, age, religion, and caste status. To account for caste, an important marker of social disadvantage in India, we included the respondent's caste among our explanatory variables. Respondent's economic status was determined by including wealth quintiles, education levels, partner's education levels, employment status (work for wages or not), current residence (rural versus urban; dummy variables for state of residence).

Logistic regression techniques were used to analyse the links between anaemia and dietary habits after controlling for an array of socioeconomic and demographic characteri stics of the respondent. STATA11 (StataCorp. 2009. Stata: Release 11. Statistical Software. College Station, TX: StataCorp LP) was used for all data analyses.

\section{Results}

Table 1 indicates that $40 \%$ of the respondents had no education, and the figure was $23 \%$ for participants' husbands. The Table also shows that $27 \%$ of the population of interest never consumed meat, fish, and eggs, but everyone in the sample ate vegetables or pulses, at least occasionally. Hinduism is the predominant religion, followed by $78 \%$ of the sample. Only $37 \%$ of the women in the sample were in wage employment. A significant proportion of the sample is either severely underweight/underweight (27\%) or overweight/obese (18\%).

Figure 1 depicts the respondents' anaemia status with key variables.

The figure shows that residence in a food insecure state, poverty, and caste are good predictors of the prevalence of anaemia. The difference is particularly accentuated between the wealth quintiles, with the poorest quintile having 10 percentage points higher prevalence of moderate or severe 
TABLE 1: Study variables and covariates, 2005-06 Indian National Family and Health Survey of Women.

\begin{tabular}{|c|c|}
\hline Variables & $\begin{array}{c}\text { Sample size }=81301 \text { ratio (or } \\
\text { number for "Age" and "Average } \\
\text { number of children") }\end{array}$ \\
\hline Anaemic (moderate and severe) & 0.16 \\
\hline \multicolumn{2}{|c|}{ Socioeconomic and demographic characteristics } \\
\hline Age (in years) & 32.55 \\
\hline Average number of children & 2.77 \\
\hline Scheduled caste & 0.17 \\
\hline Scheduled tribe & 0.12 \\
\hline Backward tribe & 0.33 \\
\hline Other caste & 0.33 \\
\hline Caste-do not know & 0.04 \\
\hline Religion-Hindu/Sikh & 0.78 \\
\hline Religion-Muslim/Christian & 0.19 \\
\hline Religion-Jain/Buddhist & 0.02 \\
\hline Other religions & 0.01 \\
\hline BMI: severely underweight & 0.08 \\
\hline BMI: underweight & 0.19 \\
\hline BMI: normal & 0.55 \\
\hline BMI: overweight & 0.14 \\
\hline BMI: obese & 0.04 \\
\hline pregnant & 0.06 \\
\hline Working & 0.37 \\
\hline No schooling & 0.40 \\
\hline Completed Primary schooling & 0.16 \\
\hline Secondary schooling and above & 0.44 \\
\hline Spouse of household head & 0.65 \\
\hline $\begin{array}{l}\text { Husband's education-no } \\
\text { schooling }\end{array}$ & 0.23 \\
\hline $\begin{array}{l}\text { Husband's } \\
\text { education-completed primary } \\
\text { schooling }\end{array}$ & 0.16 \\
\hline $\begin{array}{l}\text { Husband's } \\
\text { education-secondary schooling } \\
\text { and above }\end{array}$ & 0.61 \\
\hline Wealth quintile_-1st (poorest) & 0.13 \\
\hline Wealth quintile-2nd & 0.16 \\
\hline Wealth quintile-3rd & 0.19 \\
\hline Wealth quintile -4 th & 0.23 \\
\hline Wealth quintile -5 th & 0.28 \\
\hline Piped water & 0.32 \\
\hline Rural & 0.58 \\
\hline \multicolumn{2}{|l|}{ Diet-related variables } \\
\hline Never consumes meat & 0.27 \\
\hline Consumes meat daily & 0.12 \\
\hline $\begin{array}{l}\text { Consumes meat } \\
\text { occasionally/weekly }\end{array}$ & 0.61 \\
\hline $\begin{array}{l}\text { Never consumes green leafy } \\
\text { vegetables/pulses }\end{array}$ & 0.00 \\
\hline $\begin{array}{l}\text { Consumes green leafy } \\
\text { vegetables/pulses daily }\end{array}$ & 0.77 \\
\hline
\end{tabular}

TABle 1: Continued.

\begin{tabular}{lc}
\hline Variables & $\begin{array}{c}\text { Sample size }=81301 \text { ratio (or } \\
\text { number for "Age" and "Average } \\
\text { number of children") }\end{array}$ \\
\hline $\begin{array}{l}\text { Consumes green leafy } \\
\text { vegetables/pulses } \\
\text { weekly/occasionally }\end{array}$ & 0.23 \\
$\begin{array}{l}\text { Never consumes dairy products } \\
\text { Consumes dairy products daily }\end{array}$ & 0.13 \\
$\begin{array}{l}\text { Consumes dairy products } \\
\text { weekly/occasionally }\end{array}$ & 0.39 \\
$\begin{array}{l}\text { Never consumes fruit } \\
\text { Consumes fruits daily } \\
\text { Consumes fruit } \\
\text { weekly/occasionally }\end{array}$ & 0.48 \\
\hline
\end{tabular}

anaemia relative to the wealthiest quintile. A similar pattern is observed between the castes, with the lowest castes/tribes having a higher prevalence of anaemia than the highest castes. In contrast to what has been found in studies looking at American populations [33], overweight and obese Indian women are less likely of being severely or moderately anaemic than Indian women with a normal BMI. A similar trend was observed in a smaller study using a previous NFHS dataset [34]. Our data analysis revealed that while women from the poorest quintile account for $0.01 \%$ of women with a BMI over 25, women from the richest quintile account for $60 \%$ of overweight/obese women in India.

Table 2 presents detailed estimates of the odds-ratios for associations of anaemia with diet, socioeconomic, and demographic factors. We present estimates for the full sample, a sample restricted to nonpregnant women and a sample restricted to three most food secure states in India.

Based on the Food Security Atlas developed by the Indian government, the 3 most "food secure" states are Kerala, Punjab, and Himachal Pradesh. Although a wide variety of variables were controlled for in the model presented in Table 2, we focus mainly on diet-related factors and briefly discuss the influence of economic factors. After controlling for potentially confounding individual and socioeconomic characteristics, we found negative and statistically significant associations between eating red meat, chicken, fish, or eggs daily and moderate to severe anaemia. Consumption of meat, fish, or eggs daily reduced the likelihood of being anaemic in the full sample (by $11 \%, P<0.05$ ), among nonpregnant women (by 11\%, $P<0.05$ ) and among women from the food secure states (by $52 \%, P<0.00$ ). Surprisingly, the consumption of milk and dairy products daily and weekly reduced likelihood of anaemia by $11 \%$ and $10 \%(P<0.05)$, respectively, among women in the full sample. This result is counterintuitive as dairy products constitute a common source of dietary calcium. Calcium is known to inhibit iron absorption in single meal studies. However, multiple meal studies, which mirror the dietary intake of the sample of interest, showed no significant effect of milk and dairy consumption on dietary iron absorption [35]. It is also plausible that, in India, milk and dairy products are proxy 
TABle 2: Associations of diet-related, socioeconomic, and demographic characteristics with moderate or severe anaemia: National Family Health Survey, 2005-06.

\begin{tabular}{|c|c|c|c|c|c|c|}
\hline \multirow{3}{*}{ Obs. } & \multicolumn{2}{|c|}{ Full sample } & \multicolumn{2}{|c|}{ Nonpregnant } & \multicolumn{2}{|c|}{ Food secure } \\
\hline & \multirow{2}{*}{ OR } & \multirow{2}{*}{$\begin{array}{c}\text { (s.e.) } \\
81,301\end{array}$} & \multirow{2}{*}{ OR } & \multirow{2}{*}{$\begin{array}{c}\text { (s.e.) } \\
76,562\end{array}$} & \multirow{2}{*}{ OR } & \multirow{2}{*}{$\begin{array}{l}\text { (s.e.) } \\
7,220 \\
\end{array}$} \\
\hline & & & & & & \\
\hline \multicolumn{7}{|l|}{ Diet-related variables } \\
\hline Eats meat daily & $0.89 * *$ & $(0.04)$ & $0.89 * *$ & $(0.05)$ & $0.48^{* * *}$ & $(0.06)$ \\
\hline Eats meat weekly/occasionally & 1.00 & $(0.03)$ & 0.99 & $(0.03)$ & $0.79^{* *}$ & $(0.08)$ \\
\hline Eats green leafy vegetables daily & 0.69 & $(0.28)$ & 0.62 & $(0.24)$ & 0.32 & $(0.30)$ \\
\hline Eats green leafy vegetables weekly/occasionally & 0.70 & $(0.28)$ & 0.62 & $(0.24)$ & 0.32 & $(0.30)$ \\
\hline Eats dairy products daily & $0.89 * * *$ & $(0.03)$ & $0.90^{* * *}$ & $(0.03)$ & 0.88 & $(0.12)$ \\
\hline Eats dairy products weekly/occasionally & $0.90^{* * *}$ & $(0.03)$ & $0.92^{* *}$ & $(0.03)$ & 0.80 & $(0.11)$ \\
\hline Eats fruits daily & 0.98 & $(0.06)$ & 0.99 & $(0.07)$ & 1.04 & $(0.28)$ \\
\hline Eats fruits weekly/occasionally & 1.04 & $(0.06)$ & 1.05 & $(0.06)$ & 1.12 & $(0.27)$ \\
\hline \multicolumn{7}{|l|}{ Socioeconomic and demographic characteristics } \\
\hline Number of children & $1.02^{* * *}$ & $(0.01)$ & $1.02^{* *}$ & $(0.01)$ & $1.07^{*}$ & $(0.04)$ \\
\hline Employed & $0.96^{* *}$ & $(0.02)$ & $0.96^{*}$ & $(0.02)$ & 0.87 & $(0.08)$ \\
\hline Education level-primary & 1.02 & $(0.03)$ & 1.04 & $(0.03)$ & 1.23 & $(0.16)$ \\
\hline Education level-higher than elementary & 0.96 & $(0.03)$ & 0.98 & $(0.03)$ & 1.23 & $(0.17)$ \\
\hline Piped water for drinking & $0.95^{*}$ & $(0.03)$ & $0.95^{*}$ & $(0.03)$ & 1.12 & $(0.11)$ \\
\hline Muslims and Christians & $0.92^{* *}$ & $(0.03)$ & $0.92^{* *}$ & $(0.04)$ & 1.08 & $(0.16)$ \\
\hline Jain and Buddhist & $0.83^{*}$ & $(0.08)$ & $0.84^{*}$ & $(0.09)$ & 1.23 & $(0.55)$ \\
\hline Other religion & 0.87 & $(0.11)$ & 0.87 & $(0.12)$ & $3.29 * *$ & $(1.86)$ \\
\hline Spouse & 0.97 & $(0.02)$ & $0.95^{* *}$ & $(0.02)$ & 0.94 & $(0.08)$ \\
\hline BMI: severely underweight & $1.25^{* * *}$ & $(0.05)$ & $1.30^{* * *}$ & $(0.05)$ & 1.18 & $(0.22)$ \\
\hline BMI: underweight & $1.23^{* * *}$ & $(0.03)$ & $1.28^{* * *}$ & $(0.03)$ & 1.20 & $(0.16)$ \\
\hline BMI: overweight & $0.67^{* * *}$ & $(0.02)$ & $0.64^{* * *}$ & $(0.02)$ & $0.66^{* * *}$ & $(0.07)$ \\
\hline BMI: obese & $0.62^{* * *}$ & $(0.04)$ & $0.62^{* * *}$ & $(0.04)$ & 0.90 & $(0.14)$ \\
\hline Husband's education-primary & $0.94^{*}$ & $(0.03)$ & $0.95^{*}$ & $(0.03)$ & 0.91 & $(0.13)$ \\
\hline Husband's edu. Higher than primary & $0.89^{* * *}$ & $(0.03)$ & $0.89^{* * *}$ & $(0.03)$ & $0.75^{* *}$ & $(0.10)$ \\
\hline Scheduled caste & $1.12^{* * *}$ & $(0.04)$ & $1.13^{* * *}$ & $(0.04)$ & 1.20 & $(0.13)$ \\
\hline Scheduled tribe & $1.33^{* * *}$ & $(0.06)$ & $1.32^{* * *}$ & $(0.06)$ & 1.33 & $(0.44)$ \\
\hline Backward caste & 1.03 & $(0.03)$ & 1.03 & $(0.03)$ & $1.35^{* *}$ & $(0.18)$ \\
\hline Caste-do not know & 0.94 & $(0.06)$ & 0.94 & $(0.06)$ & 0.84 & $(0.21)$ \\
\hline Wealth Quintile-2nd & $0.90^{* * *}$ & $(0.03)$ & $0.91^{* *}$ & $(0.04)$ & 0.67 & $(0.29)$ \\
\hline Wealth Quintile-3rd & $0.86^{* * *}$ & $(0.03)$ & $0.87^{* * *}$ & $(0.04)$ & 0.63 & $(0.23)$ \\
\hline Wealth Quintile-4th & $0.84^{* * *}$ & $(0.04)$ & $0.87^{* * *}$ & $(0.04)$ & 0.75 & $(0.27)$ \\
\hline Wealth Quintile-5th & $0.76^{* * *}$ & $(0.04)$ & $0.78^{* * *}$ & $(0.05)$ & 0.61 & $(0.23)$ \\
\hline Rural & $0.92^{* * *}$ & $(0.03)$ & $0.92^{* *}$ & $(0.03)$ & 1.04 & $(0.11)$ \\
\hline Pregnant & $2.76^{* * *}$ & $(0.10)$ & & & $2.45^{* * *}$ & $(0.42)$ \\
\hline Age & $0.96^{* * *}$ & $(0.01)$ & $0.95^{* * *}$ & $(0.01)$ & $0.90^{* *}$ & $(0.04)$ \\
\hline Age: squared & $1.00^{* * *}$ & $(0.00)$ & $1.00^{* * *}$ & $(0.00)$ & $1.00^{* * *}$ & $(0.00)$ \\
\hline Food secure: Himachal Pradesh & 0.96 & $(0.11)$ & 0.99 & $(0.12)$ & & \\
\hline Food secure: Kerala & $0.64^{* * *}$ & $(0.07)$ & $0.65^{* * *}$ & $(0.07)$ & & \\
\hline Food secure: Punjab & 1.02 & $(0.08)$ & 1.02 & $(0.08)$ & & \\
\hline Food insecure: Bihar & 1.07 & $(0.09)$ & 1.10 & $(0.09)$ & & \\
\hline Food insecure: Jharkhand & $1.16^{*}$ & $(0.09)$ & $1.18^{*}$ & $(0.10)$ & & \\
\hline Food insecure: Madhya Pradesh & $0.90^{*}$ & $(0.06)$ & 0.90 & $(0.06)$ & & \\
\hline Constant & 0.52 & $(0.23)$ & 0.65 & $(0.28)$ & 2.87 & $(3.43)$ \\
\hline
\end{tabular}

Only selected state dummies are presented. ${ }^{* * *}, * *$ and $*$ indicate statistical significance at $1 \%, 5 \%$, and $10 \%$, respectively. 
for varied dietary intake and socioeconomic prosperity [36]. The consumption of pulses, green leafy vegetables, and fruits had no statistically significant impact on anaemia status.

Socioeconomic variables such as the respondent being from a Scheduled tribe or a Scheduled caste are statistically significant and positively correlated with the likelihood of being anaemic. The generally low economic status of people from these disadvantaged castes, which restricts their ability to purchase nutritious food, is the most likely explanation for this result. Economic factors such as being in paid employment and being from a higher wealth quintile are all significantly and negatively associated with iron-deficiency anaemia. Compared to women from the poorest wealth quintile, the higher wealth quintile is statistically significant and negatively associated with the odds of being anaemic. Being from the wealthiest quintile was associated with a $24 \%(P<0.01)$ lower odds of being anaemic, relative to being from the poorest wealth quintile. Interestingly, after controlling for other factors, rural women had lower odds of being anaemic. Not surprisingly, being pregnant increased the odds of being anaemic by $73 \%(P<0.00)$.

\section{Discussion}

This study has several limitations. First, it is based on crosssectional data, and we therefore could not establish a causal relationship. However, the large population studied as well as the stratified random sampling method used in collecting data for the NFHS-3 lends credence to the reliability of our results. Second, as only haemoglobin levels were measured among participants in the survey, we had to estimate the proportion of anaemic women likely to be experiencing iron-deficiency anaemia based on published research studies. Incorporation of serum ferritin estimates into future studies will increase the validity of iron-deficiency anaemia estimates among Indian women [37]. Third, NFHS-3 did not collect data on the quantity consumed of each of the food groups. Nevertheless, even if it is assumed that all Indian women in the sample ate large quantities of the foods documented in the survey instead of the moderate food consumption characteristic of Indians, it is likely that many of those women would still have been iron deficient given the low iron content of most staple foodstuffs in India.

A major contribution of our paper is its statistically robust conclusions based on nationally representative data. Our results indicate that a diet based on daily (or several times weekly) consumption of meat, fish, chicken, or egg was significantly associated with lower levels of anaemia among Indian women. This result is robust across different models. Our finding of a negative relationship between iron-deficiency anaemia and household wealth is consistent with findings that, in many developing countries and among poor cohorts in rich nations, poverty is a root cause of iron-deficiency anaemia [38-40]. In India, our data shows that an equally important root cause is vegetarianism, as $27 \%$ of women have a fairly strict vegetarian diet, defined as a diet without red meat, chicken, fish, and eggs. Poverty alone cannot fully account for iron-deficiency anaemia among Indian women, given the consistently lower prevalence of anaemia among women in poorer neighbouring states of Pakistan and Bangladesh [1]. Vegetarian diet significantly influences the development of iron-deficiency anaemia in India via avoidance of meat and consumption of low quality and quantity of iron-rich foodstuff. In wealthy nations such as Australia, knowledge of the importance of iron-rich foods in diet, iron fortification of vegetarian diets, and easy availability as well as affordability of iron-rich vegetarian diets has reduced the impact of vegetarianism on iron-deficiency. For example, $8 \%$ of preschool children, $12 \%$ of pregnant women, and $15 \%$ of nonpregnant women of reproductive age in Australia have anaemia, with iron-deficiency identified as a major cause. These anaemia prevalence rates are about a third of the anaemia prevalence rates in India $[37,38]$.

Food-based strategies to address iron-deficiency among Indian women include consumer education to encourage diversification of the diet to include iron-rich foods, improving popularity and consumer accessibility to foods and fruits that contain vitamin $\mathrm{C}$, which enhances iron absorption [41], as well as behaviour modification to encourage women to avoid consuming tea with meals as tea may interfere with iron absorption. An iron-rich food source worth promoting is millet (Ragi ganji), either as roti bread or as malt beverage. Ragi ganji has higher iron content than rice and maize, and less iron-inhibiting phytates than rice wheat and maize [22, 42] Biofortification policies to promote food crops with higher iron content are potentially useful, subject to overcoming technical obstacles. Biotechnology may also provide crops with decreased phytate content and, hence, less interference with iron absorption. A strategy of using ferrous sulphate or ferric pyrophosphate for rice and flour fortification may provide up to $40 \%$ of the recommended daily intake of iron from these commonly consumed foodstuffs alone [41-43].

Although food fortification is a cost-effective strategy for addressing iron-deficiency anaemia, it would be difficult to implement this strategy effectively in India where production of staple foodstuff, such as rice milling or flour processing, is not centralized [44]. Flour fortification in India started in 1998 when the Kapoor Brothers Roller Mills and Vinod Mills began voluntary fortification. Following the implementation of the India Micronutrient National Investment Plan for 2007-2011, voluntary food fortification is being augmented by state and national policies, such as fortification of all subsidised wheat flour distributed to poor families with iron and folic [45]. This initiative is generally well accepted, and many States, such as Gujarat, West Bengal, and Tamil Nadu have policies for mandatory fortification of roller mill flour with iron and folic acid. Nevertheless, given the potentially high implementation cost and likely asymmetrical impact of iron fortification strategy in India, iron supplementation programs for women and children in food insecure states may be concurrently implemented. It is also important to implement effective programs for the prevention of malaria and hookworm, which contribute substantially to iron-deficiency in some rural regions of India. A coordinated and sustained health education approach to improve knowledge, 
attitude, and practice in relation to addressing iron-deficiency among Indian women has been shown by local studies to be useful in making appropriate dietary choices [46].

\section{Conclusion}

Recent estimates of iron-deficiency anaemia show that 52\% of Indian women aged 15-49 years are anaemic. Our findings highlight the important role of dietary factors in mediating the development of iron-deficiency anaemia. In particular, vegetarian women in India are significantly more likely to be iron deficient compared with their omnivorous counterparts. The finding that wealthier females are significantly less likely to be anaemic suggests that poverty reduction is crucial to reduce the incidence of iron-deficiency among Indian women. However, even among the poor, women subsisting on vegetarian diets were significantly more likely to be anaemic. Mass food fortification with iron $[47,48]$, targeted iron supplementation, control of hookworm and malaria, and effective public education about iron-rich sources of plantbased and animal-based foods are effective strategies for reducing the incidence and prevalence of iron-deficiency anaemia among Indian women.

\section{Conflict of Interests}

The authors declare that there is no conflict of interests. This research was self-funded and received no specific grant from any funding agency in the public, commercial, or not-forprofit sectors.

\section{References}

[1] World Health Organization, World-Wide Prevalence of Anaemia, 1993 to 2005, World Health Organization, Geneva, Switzerland, 2008.

[2] F. S. Asobayire, P. Adou, L. Davidsson, J. D. Cook, and R. F. Hurrell, "Prevalence of iron deficiency with and without concurrent anemia in population groups with high prevalences of malaria and other infections: a study in Côte d'Ivoire," The American Journal of Clinical Nutrition, vol. 74, no. 6, pp. 776782, 2001.

[3] R. J. Stoltzfus, "Defining iron-deficiency anemia in public health terms: a time for reflection," Journal of Nutrition, vol. 131 , no. 2 , pp. 565 s- 567 s, 2001.

[4] World Health Organization, Global Health Risks: Mortality and Burden of Disease Attributable to Selected Major Risks, World Health Organization, Geneva, Switzerland, 2009.

[5] B. J. Brabin, M. Hakimi, and D. Pelletier, "An analysis of anemia and pregnancy-related maternal mortality," Journal of Nutrition, vol. 131, no. 2, pp. 604S-614S, 2001.

[6] B. J. Brabin, Z. Premji, and F. Verhoeff, "An analysis of anemia and child mortality," Journal of Nutrition, vol. 131, no. 2, pp. 636S-645S, 2001.

[7] K. S. Khan, D. Wojdyla, L. Say, A. M. Gülmezoglu, and P. F. Van Look, "WHO analysis of causes of maternal death: a systematic review," The Lancet, vol. 367, no. 9516, pp. 1066-1074, 2006.

[8] H. Sachdev, T. Gera, and P. Nestel, "Effect of iron supplementation on mental and motor development in children: Systematic review of randomised controlled trials," Public Health Nutrition, vol. 8, no. 2, pp. 117-132, 2005.
[9] D. L. Kasper, E. Braunwald, A. S. Fauci et al., Harrison's Principles of Internal Medicine, part 6, section two: hematopoietic disorders, McGraw-Hill Medical, New York, NY, USA, 17th edition, 2008.

[10] World Health Organization, Iron Deficiency Anaemia: Assessment, Prevention and Control-A Guide for Programme Managers, World Health Organization, Geneva, Switzerland, 2001.

[11] World Health Organization, Assessing the Iron Status of Populations, World Health Organization, Geneva, Switzerland, 2nd edition, 2007.

[12] P. V. Kotecha, "Micronutrient malnutrition in India: let us say "no" to it now," The Indian Journal of Community Medicine, vol. 33, pp. 9-10, 2008.

[13] S. Seshadri, "Prevalence of micronutrient deficiency particularly of iron, zinc and folic acid in pregnant women in South East Asia," The British Journal of Nutrition, vol. 85, no. 2, pp. S87-S92, 2001.

[14] Ministry of Health and Family Welfare, Government of India, Micronutrient National Investment Plan (IMNIP) for 20072011, Ministry of Health and Family Welfar, New Delhi, India, 2006.

[15] Ministry of Health and Family Welfare, Government of India, Addressing Iron Deficiency Anaemia among Indian Adolescents-12 by 12 Initiative, Ministry of Health and Family Welfare, New Delhi, Indaia, 2007.

[16] T. Dietz, A. S. Frisch, L. Kalof, P. C. Stern, and G. A. Guagnano, "Values and vegetarianism: an exploratory analysis," Rural Sociology, vol. 60, pp. 533-542, 1995.

[17] G. D. Flood, An Introduction to Hinduism, Cambridge University Press, New York, NY, USA, 1996.

[18] P. Taylor, C. Martinez-Torres, I. Leets, J. Ramirez, M. N. Garcia-Casal, and M. Layrisse, "Relationships among iron absorption, percent saturation of plasma transferrin and serum ferritin concentration in humans," Journal of Nutrition, vol. 118, no. 9, pp. 1110-1115, 1988.

[19] Food and Nutrition Board, Institute of Medicine, Dietary Reference Intakes for Vitamin A, Vitamin K, Arsenic, Boron, Chromium, Copper, Iodine, Iron, Manganese, Molybdenum, Nickel, Silicon, Vanadium, and Zinc, National Academy Press, Washington, DC, USA, 2001.

[20] C. A. Venti and C. S. Johnston, "Modified food guide pyramid for lactovegetarians and vegans," Journal of Nutrition, vol. 132, no. 5, pp. 1050-1054, 2002.

[21] N. R. Reddy and S. K. Sathe, Food Phytates, CRC Press, Florida, Fla, USA, 2001.

[22] I. M. Zijp, O. Korver, and L. B. M. Tijburg, "Effect of tea and other dietary factors on iron absorption," Critical Reviews in Food Science and Nutrition, vol. 40, no. 5, pp. 371-398, 2000.

[23] M. A. Galvin, M. Kiely, and A. Flynn, "Impact of ready-to-eat breakfast cereal (RTEBC) consumption on adequacy of micronutrient intakes and compliance with dietary recommendations in Irish adults," Public Health Nutrition, vol. 6, no. 4, pp. 351-363, 2003.

[24] S. Hercberg, P. Preziosi, and P. Galan, "Iron deficiency in Europe," Public Health Nutrition, vol. 4, no. 2 B, pp. 537-545, 2001.

[25] Micronutrient Initiative Wheat Flour Fortification in India, MI, New Delhi, India, 2007.

[26] L. H. Allen, "To what extent can food-based approaches improve micronutrient status?” Asia Pacific Journal of Clinical Nutrition, vol. 17, no. 1, pp. 103-105, 2008.

[27] B. Lonnerdal, "Soybean ferritin: implications for iron status of vegetarians," The American Journal of Clinical Nutrition, vol. 89 , no. 5, pp. 1680S-1685S, 2009. 
[28] I. S. Rajan and K. S. James, "Second national family health survey: emerging issues," Economic and Political Weekly, vol. 39, pp. 647-651, 2004.

[29] M. Franchini, G. L. Salvagno, M. Montagnana, and G. Lippi, "Serum ferritin levels correlate with haemoglobin concentration: a report on 589 outpatients from a single centre," Blood Transfusion, vol. 5, no. 4, pp. 244-245, 2007.

[30] J. A. Haidar and R. S. Pobocik, "Iron deficiency anemia is not a rare problem among women of reproductive ages in Ethiopia: a community based cross sectional study," BMC Blood Disorders, vol. 9, article 1471, p. 7, 2009.

[31] E. Ugwuja, E. Akubugwo, U. Ibiam, and O. Onyechi, "Impact of maternal iron deficiency and anaemia on pregnancy and its outcomes in a Nigerian population," The Internet Journal of Nutrition and Wellness, vol. 10, p. 1, 2010.

[32] S. M. Z. Hyder, L. Persson, M. Chowdhury, B. Lönnerdal, and E. C. Ekström, "Anaemia and iron deficiency during pregnancy in rural Bangladesh," Public Health Nutrition, vol. 7, no. 8, pp. 1065-1070, 2004.

[33] E. J. Adams, L. Grummer-Strawn, and G. Chavez, "Food insecurity is associated with increased risk of obesity in California women," Journal of Nutrition, vol. 133, no. 4, pp. 1070-1074, 2003.

[34] P. L. Griffiths and M. E. Bentley, "The nutrition transition is underway in India," Journal of Nutrition, vol. 131, no. 10, pp. 2692-2700, 2001.

[35] S. R. Lynch, "The effect of calcium on iron absorption," Nutrition Research Reviews, vol. 13, no. 2, pp. 141-158, 2000.

[36] N. P. Nawani, Report of the Regional Expert Consultation on the Indian Experience on Household Food and Nutrition Security Held in Bangkok, Thailand from 8 to 11 August 1994, RAP, Bangkok, Thailand, 2004.

[37] S. S. Pasricha, S. C. Flecknoe-Brown, K. J. Allen et al., "Diagnosis and management of iron deficiency anaemia: a clinical update," Medical Journal of Australia, vol. 193, no. 9, pp. 525-532, 2010.

[38] M. E. Bentley and P. L. Griffiths, "The burden of anemia among women in India," European Journal of Clinical Nutrition, vol. 57, no. 1, pp. 52-60, 2003.

[39] A. A. Adish, S. A. Esrey, T. W. Gyorkos, and T. Johns, "Risk factors for iron deficiency anaemia in preschool children in northern Ethiopia," Public Health Nutrition, vol. 2, no. 3, pp. 243-252, 1999.

[40] L. M. Bodnar, M. E. Cogswell, and K. S. Scanlon, "Low income postpartum women are at risk of iron deficiency," Journal of Nutrition, vol. 132, no. 8, pp. 2298-2302, 2002.

[41] T. P. Appanah, B. Oogarah-Pratap, and A. Ruggoo, "Awareness and consumption of iron among Mauritian female factory workers," Nutrition and Food Science, vol. 39, no. 2, pp. 168$175,2009$.

[42] A. Misra, K. Rastogi, and S. R. Joshi, "Whole grains and health: perspective for Asian Indians," Journal of Association of Physicians of India, vol. 57, no. 2, pp. 155-162, 2009.

[43] D. Moretti, M. B. Zimmermann, S. Muthayya et al., "Extruded rice fortified with micronized ground ferric pyrophosphate reduces iron deficiency in Indian schoolchildren: a doubleblind randomized controlled trial1-3," The American Journal of Clinical Nutrition, vol. 84, no. 4, pp. 822-829, 2006.

[44] R. F. Hurrell, "Fortification: overcoming technical and practical barriers," Journal of Nutrition, vol. 132, no. 4, pp. 806S812S, 2002.

[45] A. Wesley and S. Dutta, "Update on wheat flour fortification in India," Flour Fortification Initiative, United States, 2009.

[46] M. Kaur and K. Singh, "Effect of health education on knowledge, attitude and practices about anaemia among rural women in Chandigarh," The Indian Journal of Community Medicine, vol. 26, pp. 128-132, 2001.

[47] R. Baltussen, C. Knai, and M. Sharan, "Iron fortification and iron supplementation are cost-effective interventions to reduce iron deficiency in four subregions of the world," Journal of Nutrition, vol. 134, no. 10, pp. 2678-2684, 2004.

[48] V. Mannar and E. B. Gallego, "Iron fortification: country level experiences and lessons learned," Journal of Nutrition, vol. 132, no. 4, pp. 8568-8588, 2002. 


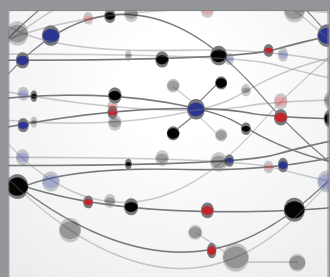

The Scientific World Journal
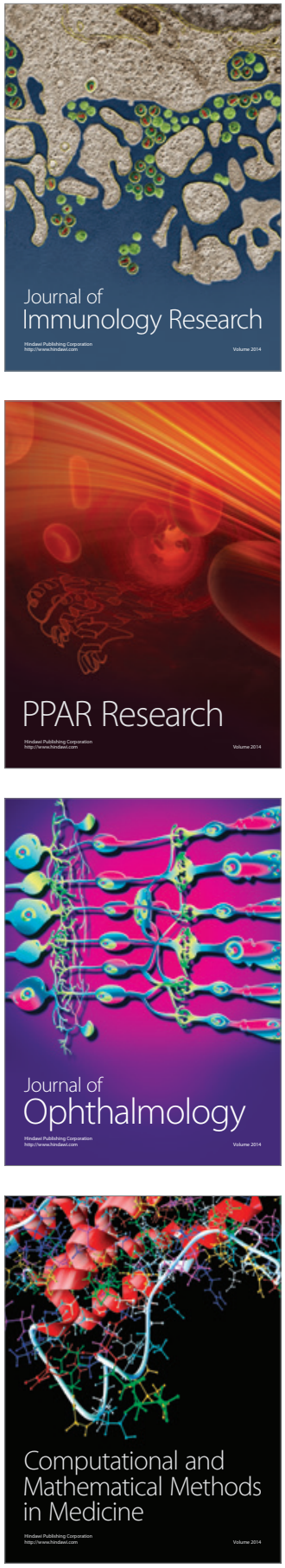

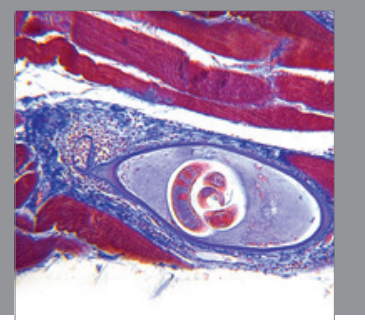

Gastroenterology

Research and Practice
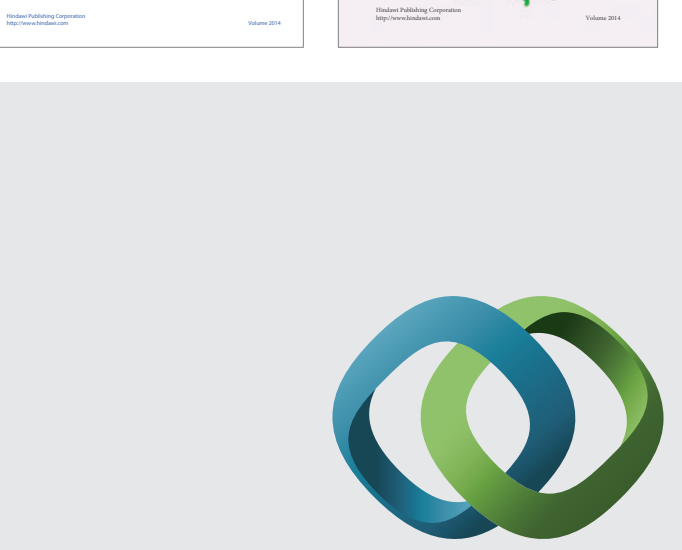

\section{Hindawi}

Submit your manuscripts at

http://www.hindawi.com
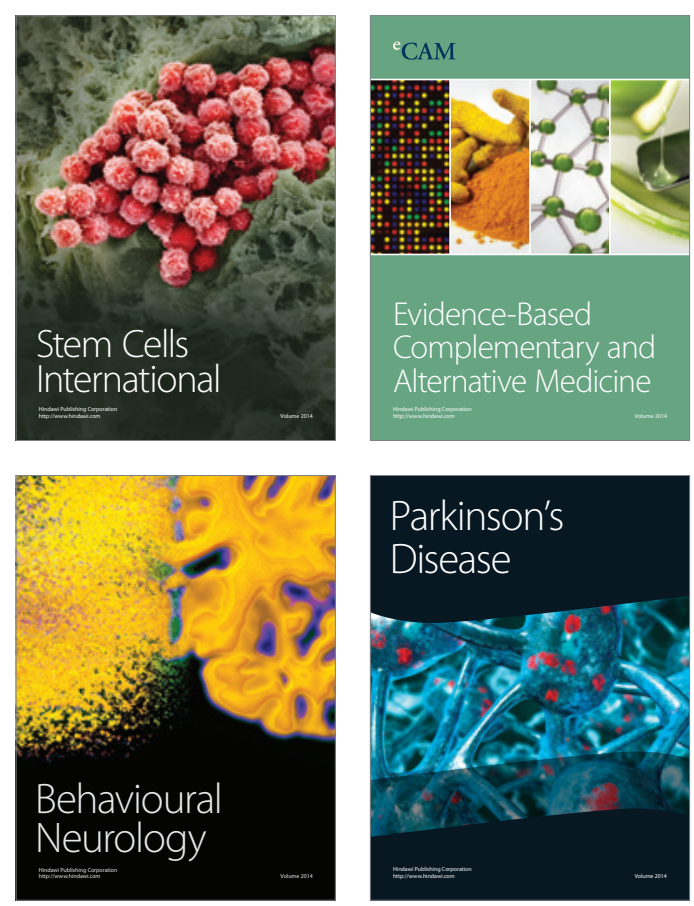

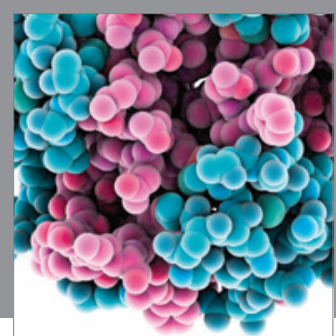

Journal of
Diabetes Research

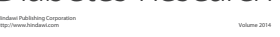

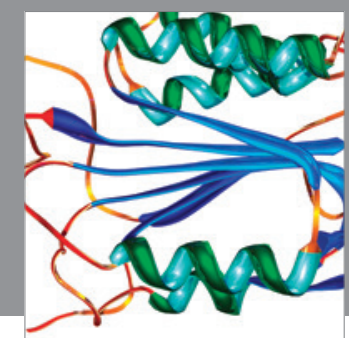

Disease Markers
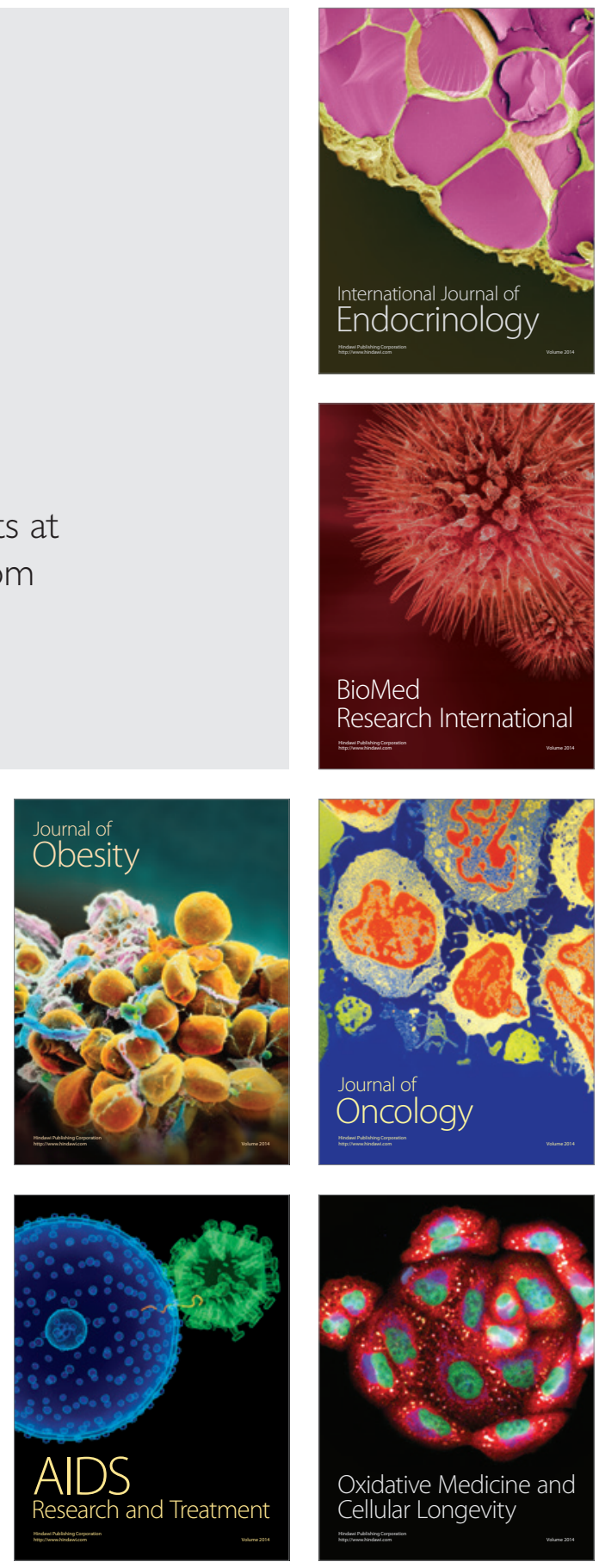